See discussions, stats, and author profiles for this publication at: https://www.researchgate.net/publication/345597808

\title{
High thematic resolution land use change models refine biodiversity scenarios: A case study with Belgian bumblebees
}

Article in Journal of Biogeography · November 2020

Dol: $10.1111 / \mathrm{jbi} .14000$

CITATIONS

6 authors, including:

Leon Marshall

Université Libre de Bruxelles

19 PUBLICATIONS 115 CITATIONS

SEE PROFILE

Pierre Rasmont

Université de Mons

333 PUBLICATIONS 5,399 CITATIONS

SEE PROFILE

Some of the authors of this publication are also working on these related projects:

Project Bee systematics and biogeography View project

Project Bee Systematics View project
READS

103

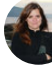

Sarah Vray

Luxembourg Institute of Science and Technology (LIST)

18 PUBLICATIONS 118 CITATIONS

SEE PROFILE

Nicolas J Vereecken

Université Libre de Bruxelles

272 PUBLICATIONS 1,858 CITATIONS

SEE PROFILE 


\title{
High thematic resolution land use change models refine biodiversity scenarios: A case study with Belgian bumblebees
}

\author{
Leon Marshall ${ }^{1,2,3}$ (D) | Veronique Beckers ${ }^{3,4}$ | Sarah Vray, ${ }^{5,6}$ | Pierre Rasmont $^{6}$ | \\ Nicolas J. Vereecken ${ }^{1}$ | Nicolas Dendoncker ${ }^{3}$
}

\begin{abstract}
${ }^{1}$ Agroecology Lab, Université libre de Bruxelles (ULB), Brussels, Belgium

${ }^{2}$ Naturalis Biodiversity Center, Leiden, The Netherlands

${ }^{3}$ Department of Geography, Institute of Life, Earth and Environment (ILEE), University of Namur, Namur, Belgium

${ }^{4}$ Geography and Tourism Research Group, Department Earth and Environmental Science, KU Leuven, Heverlee, Belgium

${ }^{5}$ Environmental Research and Innovation Department, Luxembourg Institute of Science and Technology (LIST), Belvaux, Luxembourg

${ }^{6}$ Laboratoire de Zoologie, Research Institute of Biosciences, University of Mons, Mons, Belgium
\end{abstract}

\section{Correspondence}

Leon Marshall, Agroecology Lab, Université libre de Bruxelles (ULB), Boulevard du Triomphe CP 264/2, B 1050 Brussels, Belgium.

Email: leon.marshall@ulb.ac.be

Funding information

Belgian Federal Science Policy Office, Grant/Award Number: BR/121/A2/MASC and $B R / 132 / A 1 / B E L B E E S$

Handling Editor: Jack Williams

\begin{abstract}
Aim: Projections of biodiversity scenarios often rely solely on climate change to inform species distribution shifts in the future. Land use projections are rarely used due to their unavailability and, when available, are often at coarse spatial and thematic resolutions, making them unsuitable to capture fine scale habitat suitability. This study aims to (a) show how coupled land use change (LUC) models of high thematic resolution (HTR) can be used in species distribution models (SDM), (b) compare the impacts of HTR and low thematic resolution (LTR) explanatory predictors on biodiversity scenarios and (c) assess the impact of species' present area of occupancy on the effect of thematic resolution in SDMs.

Location: Belgium

Taxon: Bumblebees (Bombus)

Methods: We compared species distribution models with 17 land use predictors (HTR) against models with 5 land use predictors (LTR). We modelled the distribution of 17 bumblebee species in Belgium projected until 2035. We examined how model performance, variable importance and projections of distribution change differed depending on the thematic resolution of the land use predictors.

Results: Overall, HTR models performed better than LTR models. LTR models predicted greater extent per species. HTR projected a greater percentage of range gains, and both models projected similar losses of suitable habitat. However, the percentage loss and connectivity of suitable habitats varied differently for HTR and LTR models along a gradient of rare to common species. The HTR models projected greater loss of suitable areas for rare species and less loss for common species compared to LTR models.

Main conclusions: These results illustrate the importance of using ecologically relevant explanatory variables in SDMs, particularly for rare and localized species with specific habitat requirements. The results also indicate the need for large-scale LUC projections to improve future biodiversity scenarios under climate change and to improve the ability of conservationists and policymakers to use SDM projections.
\end{abstract}




\section{KEYWORDS}

agent-based models, agriculture, biodiversity loss, cellular automata, grassland, range shift, species distribution modelling, urban, wild bees

\section{1 | INTRODUCTION}

Biodiversity loss in the Anthropocene is occurring at a speed far greater than expected by background rates (Ceballos et al., 2015). A key methodology used to understand this loss and potentially avoid greater loss is to project the distribution of species into the future based on scenarios of environmental change, this is often achieved through a species distribution modelling (SDM) approach (Porfirio et al., 2014). At broad spatial scales, the assumption is that climate may be the main constraint to species distributions, and therefore, many future SDMs focus on climate change only (de Chazal \& Rounsevell, 2009; Sinclair et al., 2010; Titeux et al., 2016). However, at finer resolutions, the effect of land use (LU) covariates increases; landscape-specific features that provide key habitat requirements occur at this finer scale (Luoto et al., 2007; Thuiller, Araújo, et al., 2004; Thuiller, Brotons, et al., 2004). This indicates a necessity to include land use change (LUC) projections into future biodiversity scenarios but this is rarely the case because of a lack of availability or LUC projections with coarse spatial and thematic resolution (i.e. few LU classes; Titeux et al., 2016; Verburg et al., 2013).

One of the important areas where LUC models can improve is in precision of the classification of land use by including more detailed and less common LU types (De Rosa et al., 2016). This is particularly important for producing future biodiversity scenarios, as marginal LU categories often represent important habitats, particularly for rare and specialized species (Guisan et al., 2006; Guisan \& Thuiller, 2005). These improvements to LUC models will develop more precise predictors to model biodiversity patterns in the future, which will impact the quality of SDMs (Austin \& Van Niel, 2011).

Future models of species distribution often represent varying degrees of uncertainty and may differ greatly in their extent and thematic resolution (Alexander et al., 2017; Titeux et al., 2016). These differences may explain why, in many future biodiversity studies on a variety of organisms, there is no clear consensus on the impact of including LUC variables. In some cases, this has not provided different outcomes compared to models with static LU (Martin et al., 2013). Examining LUC in isolation showed improvements over using static LU for invasion dynamics (Chytrý et al., 2012; Ficetola et al., 2010) and the distribution of nesting resources (Wisz et al., 2008). LUC may modify the distribution of species but only within a general habitat suitability driven by climate change (Barbet-Massin et al., 2012; Préau et al., 2018). Finally, some other studies observe alternative distribution forecasts and greater potential loss for certain species with the inclusion of LUC predictors (Hughes et al., 2012; Marshall et al., 2018; Riordan \& Rundel, 2014; Sohl, 2014).

Alongside scale and spatial resolution, thematic resolution of predictors is an important aspect of SDM and understanding ecological patterns (Kerr \& Ostrovsky, 2003; Vicente et al., 2014). In
Mexican pines (Cord et al., 2014), corals (Rengstorf et al., 2014) and Chinese tree species (Liang et al., 2013) increased thematic resolution of predictors resulted in improved model performance. Therefore, one explanation for the variability in the effect of LUC variables in biodiversity scenarios may be the thematic resolution of the LUC projections available (Titeux et al., 2016). This leads to the hypothesis proposed by Martin et al. (2013), namely that increased thematic resolution is a necessity to better capture the potential effect of LUC on species trends. This hypothesis remains to be tested.

One modelling approach which allows for fine-scale and high thematic resolution estimations of future LUC is agent-based modelling (ABM) (Rounsevell et al., 2012). However, the combination of an agent-based model with SDM is rarely done, partly due to differences between spatial and temporal scales used by different ABM and SDM models. (Parker et al., 2003). Agent-based models are often developed to be either very detailed for a small region (Bakker et al., 2015; Happe et al., 2008) or to cover large regions, losing detailed information in the process (Rounsevell et al., 2012), making them unsuitable for producing detailed biodiversity scenarios. In this study, we utilize the output from ADAM (Agricultural Dynamics through Agent-based Modelling), which allows the modelling of a wide variety of agricultural LU types at a fine resolution and for a large spatial extent (Beckers et al., 2018), in combination with a constrained cellular automata-based LU model (CCA model) including marginal LU categories (Engelen et al., 2011). This allows for more relevant predictors to estimate habitat suitability of landscapes in SDMs.

Here, we use two sets of predictor variables from two combined fine-scale LUC model outputs to produce SDMs, one with low thematic resolution ( 5 classes) and one with high thematic resolution (17 classes), and compare the impact this has on the projected distribution of bumblebee species (genus Bombus, Apidae) in Belgium. Bumblebees represent an ideal study species to test this hypothesis. There are considerable long-term occurrence records available and, as a group, bumblebees have shown declines at the European scale (Biesmeijer et al., 2006; Carvalheiro et al., 2013; Kerr et al., 2015; Nieto et al., 2014; Polce et al., 2018; Rasmont et al., 2005). Previous research has shown that climate change alone is expected to have strong negative impacts for bumblebees at the European level (Rasmont et al., 2015). This research was expanded upon to include projected changes in LU alongside climate change, and the results suggested that for certain bumblebee species the inclusion of LUC variables resulted in greater negative impacts on their distributions in the future (Marshall et al., 2018). Here, we focus on LUC alone and assess the influence of the thematic resolution (detail and quantity of LU classes) on the projected distribution of bumblebees. For example, more detailed agriculture land use information that separates late mass flowering crops, which support less-common bumblebees 
(Kallioniemi et al., 2017) from cereal crop landscapes which only support common short-tongued bumblebees (Walther-Hellwig \& Frankl, 2000). We do not assume climate is not important for bumblebees but seek to test the effect of future land use thematic resolution separate from climate impacts, in a Belgian context. With this paper, we aim to (a) show how coupled LUC models of high thematic resolution (HTR) can be used in SDMs, (b) compare the impacts of HTR and low thematic resolution (LTR) explanatory variables on biodiversity scenarios and (c) assess the impact of species' present area of occupancy on the effect of thematic resolution in SDMs.

\section{2 | MATERIALS AND METHODS}

\section{1 | Land use change models}

The high thematic LU scenarios were based on the work of Engelen et al. (2003), Engelen et al. (2007), Engelen et al. (2011) to produce LU maps at a resolution of 1 ha from 2010 to 2035. The background LU scenarios used in this research were based upon three storylines (see Table S2.1), (a) a business as usual (BAU) storyline (a continuation of current trends of population growth and changes in population densities), (b) the Global Economy storyline (GE; high international cooperation, focus on private initiatives) and the (c) Regional Communities storyline (RC; low international cooperation, emphasis on public institutions). The assumptions implicit to the three storylines were used to produce spatially explicit LU scenarios, and subsequently maps, using a cellular automata-based LU model (CCA model) developed by Engelen et al. (2011) and based on the work of White et al., (1997). Each scenario resulted in a separate mapped projection of land use in 2035.

To create higher thematic resolution agricultural LU projections, we coupled the outputs of the CCA model with ADAM, an agentbased model that simulates, on a yearly basis, the decisions of the farming population of a whole country (Beckers et al., 2018). The two models were combined based on the Belgian LUC scenarios that resulted from the three storylines (Table S2.1, Beckers et al., 2020). We used percentage cover of each LU class as the explanatory variable in the SDMs. We aggregated the 1 ha LU maps to a grid of $1 \times 1 \mathrm{~km}$ resolution with LU percentages calculated for every grid cell (Figure 1). A similar process was done for the parcel map with the agricultural LU produced by ADAM. The presence of the different crops was translated into a percentage of the total agricultural land at the $1 \times 1 \mathrm{~km}$ resolution (Figure 1). More precisely, the crop percentages were used to split up the arable LU class generated from the LU map, by defining the relative share of each crop in the total percentage of arable land at the $1 \times 1 \mathrm{~km}$ resolution (Figure 1 ). The percentage of arable land was in that way further split up into four agricultural LU classes, namely: grains (containing the modelled amount of wheat, barley and maize), sugar beets, rapeseed and
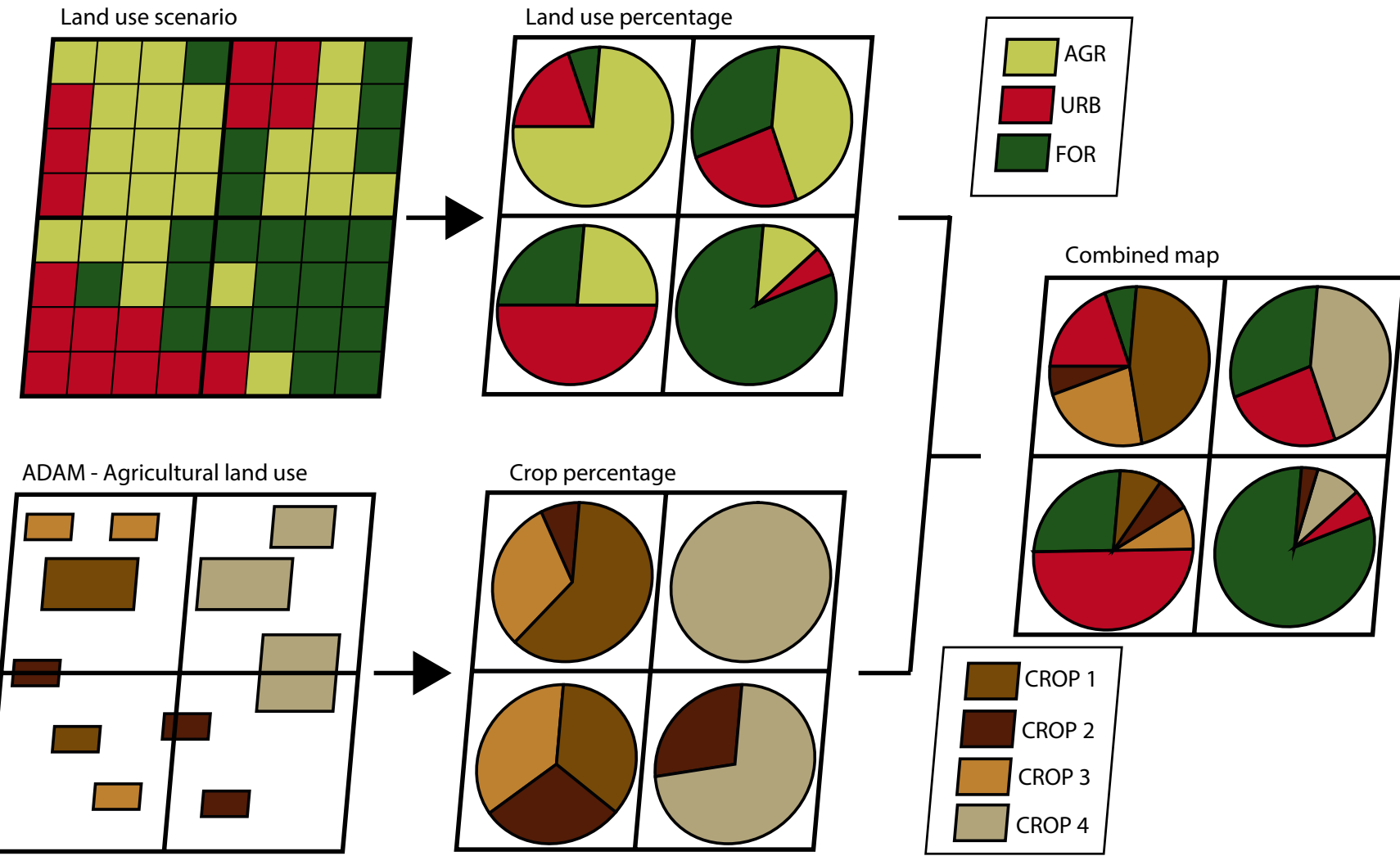

FIGURE 1 Simplified example of the integration of the ADAM model data within the background land use framework (CCA model). Land use data at 1 ha resolution (CCA model) and agricultural parcel data (ADAM) were combined at a $1 \times 1 \mathrm{~km}$ resolution at the Belgian scale 
TAB LE 1 Overview of the land use (LU) classes used in the high-resolution model and their categorization in six aggregated classes

\begin{tabular}{|c|c|c|c|c|c|}
\hline Arable & Forest & Grassland & $\begin{array}{l}\text { Permanent } \\
\text { Crops }\end{array}$ & Urban & Other $^{a}$ \\
\hline Grain crops & Mixed forest & Pasture & Fruit trees & Residential & Water \\
\hline Unregistered agricultural land & Deciduous forest & Heathland & & Parks & Dunes \\
\hline Oil seed rape & Coniferous forest & Semi-natural grassland & & Recreation & Military \\
\hline Sugar beet & & Wetland & & Sealed surfaces ${ }^{b}$ & Greenhouses \\
\hline Potatoes & & & & & Mining \\
\hline
\end{tabular}

${ }^{\text {a } O t h e r ~ w a s ~ n o t ~ i n c l u d e d ~ i n ~ a n a l y s e s . ~}$

' Industry, Commerce and services, Infrastructure and Harbour were aggregated to 'Sealed surfaces' due to high similarity in LU properties.

potatoes (Figure 1). These four classes, together with pasture, make up more than $90 \%$ of the Belgian agricultural landscape (Table S2.2). Together with the non-agricultural LU classes, there were 25 classes available to use as explanatory variables in the SDMs. For greater detail on the LUC outputs see Appendix 1 in the Supplementary Material and Beckers et al. (2020).

\section{2 | Bumblebee collection records}

This study uses bumblebee collection records from Belgium from 2010 until 2015 as they best match the present period given the available LU data. The data were extracted from the Banque de Données Fauniques de Gembloux et Mons and are available from GBIF (Rasmont et al., 2019). The data represent museum collection data, validated and verified citizen science data, and data systematically sampled as part of scientific research projects. An additional dataset consisting of bimonthly standardized field surveys conducted under supervision of N.J. Vereecken (ULB) in various urban green spaces was obtained for the Brussels Capital Region. These data were collected by netting and UV-painted pan traps every two weeks from early April until late July during 2015. We selected 17 bumblebee species with a minimum of 32 occurrences per species (Bombus soroeensis Fabricius, 1777) and a total of 13,602 occurrences (Figure S2.1).

\section{3 | Bumblebee distribution modelling}

In order to model the distribution of Belgian bumblebees we first reduced the $25 \mathrm{LU}$ classes to 22: industry, commerce and services, infrastructure, and harbour, were assumed to represent similar anthropogenic habitats and were aggregated into a single class of sealed surfaces. We tested collinearity between predictors and no combination of variables had a Pearson's correlation >0.5 (Figure S2.2). The 22 remaining $L U$ variables were categorized into six aggregated classes, to be used as the low thematic resolution input. They were classified according to Table 1 as arable, forest, grassland, permanent crops, urban areas and other. These six classes were chosen so as to be comparable to the previous research comparing future climate and LUC models for bumblebees (Marshall et al., 2018), namely the ALARM scenarios of LUC at the European Level (Spangenberg et al., 2012). We made a further decision to remove the classes classified under 'other' as these represent classes, which do not fit in the former aggregations but otherwise have no similarity, and all have, apart from water, very limited coverage in Belgium. This resulted in two separate sets of predictor variables used for the modelling, 17 high thematic resolution predictors and 5 low thematic resolution predictors. All variables were calcualted as proportions at a $1 \times 1 \mathrm{~km}$ resolution.

The bumblebee collection records are spread over multiple years. To create a single presence map of the countrywide spread of the species for training the model, the occurrences of the species from 2010 to 2015 were combined. The species is considered present and used for the model training dataset if it is present at least once in the grid cell during the period.

For all input explanatory LU variables, apart from agriculture, the percentage of LU of each class for every grid cell is constant (during the period 2010-2015), whereby the year 2010 was taken as the baseline. However, agricultural parcels are likely to show greater yearly variation. We therefore extracted the agricultural land use for each occurrence pertaining to the year it was collected. When species were found in the same area in multiple years, we extracted the agricultural land use from the year closest to the baseline (2010). The baseline agricultural data were obtained from the Integrated Administration and Control System (IACS) dataset, which has parcel level crop data collected yearly by the EU (European Commission, 2018).

In order to project future distributions of bumblebee species in Belgium we used Maximum Entropy (MaxEnt) modelling software (version 3.4.1) (Phillips \& Dudík, 2008). We created two sets of SDMs: (a) high thematic resolution with $17 \mathrm{LU}$ explanatory variables (HTR) and (b) low thematic resolution with 5 LU explanatory variables (LTR).

For both the HTR and LTR SDMs we ran MaxEnt models using fivefold cross validation with 10 repetitions. We modified the default MaxEnt arguments so that only linear and quadratic features would be fitted for all species, that is, hinge, product and threshold features were omitted in order to avoid over parameterization of the model (Merow et al., 2013). As true absences are not available (it is not possible to accurately say that a species is not present during sampling), a background sample of explanatory variables of presences and absences was created (limited to 100 times the number of occurrences per species). This background sample is only taken 
from areas where other bumblebee species had previously been collected, referred to as a target background area. This approach accounts for sampling bias by providing a more objective selection of grid cells that may be used to represent absence (Elith et al., 2011; Phillips et al., 2009) and has been shown to produce better performing models (Mateo et al., 2010).

We assessed model performance for both HTR and LTR models using the area under the curve (AUC) of the receiver operating characteristic (ROC) curve and the Boyce index (Di Cola et al., 2017). The value of the AUC is impacted by sampling size and species occurrence, meaning that comparison between models of different species is inappropriate and a single measure of acceptable model performance is inaccessible (Jiménez-Valverde \& Lobo, 2007; van Proosdij et al., 2015). Therefore, a null model was used to test the ability of our models to capture the niche requirements of a single species, by testing if the model performs significantly better than random (van Proosdij et al., 2015; Raes \& ter Steege, 2007). For each species, the AUC value of model with all occurrence records was compared against the expected AUC value of a null distribution based on 100 randomizations of the collection data within the target background area. The null models were run with the exact same MaxEnt arguments as the actual models. A model is performing well if it has an AUC value higher than a one-sided 95\% confidence interval of the null distribution of AUC values. This means the model indicates that the bumblebees had specific niche requirements that were captured by the predictors. Variable importance was measured as the percentage increase in gain as the predictors are added to the model (Phillips et al., 2006). For each variable, we also calculated a simple approximation of the general direction of the effect of each important variable (importance $>1 \%$ ) to check if aggregated classes have similar effects as their individual components. We examined the relationship between a single predictor and the probability of presence of each bumblebee species, a Pearson's correlation coefficient greater than 0.7 was considered positive, lower than -0.7 was regarded as negative.

Each of the 50 MaxEnt model runs for the two sets of predictors was projected onto the three future LUC scenarios. To create binary presence/absence maps based on the habitat suitability maps for each species we took the mean habitat suitability of the two best (highest AUC) runs from each cross-validation fold and selected a suitability threshold by looking at the largest threshold that would leave out a maximum of $10 \%$ of the occurrence records. This method is stricter and less affected by extreme localities (Radosavljevic \& Anderson, 2014) and is also robust to problems using specificity in presence only modelling (Merow et al., 2013). These binary presence/absence maps were used to analyse the range changes per species.

\subsection{Statistical analysis of distribution change}

In order to assess the impact of HTR or LTR models on the projected distributions of Belgian bumblebees we looked at four different measures of comparison between 2035 projections and present day projections: (a) percentage loss and (b) gain in range, (c) change in number of separate patches and (d) change in landscape division index. Percentage loss and gain were measured as the total number of cells lost or gained between the present and future projections divided by the number of cells occupied in the present. The two range change metrics were calculated using the 'Biomod2' package in R (version 3.3.7; Thuiller et al., 2019). In order to approximate connectivity and isolation between suitable habitats we measured the number of patches lost or gained per species and the division index. Change in number of patches is a count of all separate areas of connected (8-connected) occupied cells. The division index is the probability that two randomly chosen suitable habitat cells are not in the same patch, the division index increases as the proportion of suitable habitat in the landscape decreases and the size of suitable habitat patches also decreases (McGarigal, 2015). Both metrics were calculated using the 'FragStats' package in R (version 0.3.1; Hesselbarth et al., 2019).

Using restricted maximum likelihood, we fit multivariate mixed effects models to assess how each of the four measures (response variables) were impacted by thematic resolution of the SDM predictors. We also included scenario as a fixed effect. Furthermore, the ordered rank of occurrence values per species (Figure S2.1) was included as a fixed effect, to test the hypothesis that the increase in thematic resolution would affect rare species more than common species. Species name was included as a random effect because of the dependency between measurements for the same species and because the inherent variation between species was not the target of the analysis. We conducted model selection on each of the four mixed effects models selecting the models with the lowest Bayesian information criteria (BIC). All models were fit with a Gaussian distribution. Percentage gain was first log-transformed in order to meet the assumptions of a Gaussian distribution.

\section{RESULTS}

\section{1 | Model performance}

All models performed better than the $95 \%$ quantile of null models. However, there was considerable variation in model performance (both AUC and Boyce index) across the different species (Table 2). For all species AUC values were clearly higher (mean difference $=0.1$, $p<0.0001$ ) for the HTR models than the LTR models (Table 2).

\section{2 | Variable importance}

The importance values of the different predictors included within the two modelling approaches were consistent with the hypothesis that we observe different effects by separating LU classes. Firstly, the results showed that the importance of the predictors in each simplified class was not evenly distributed and certain predictors 
TAB LE 2 Average AUC (area under the curve) and Boyce index value per species for high (HTR) and low (LTR) thematic resolution MaxEnt species distribution models for Belgian bumblebees

\begin{tabular}{|c|c|c|c|c|c|c|c|c|}
\hline Species & \multicolumn{4}{|c|}{ High thematic resolution land use } & \multicolumn{4}{|c|}{ Low thematic resolution land use } \\
\hline B. soroeensis & 0.95 & 0.65 & $0.94 \pm 0.02$ & $0.71 \pm 0.11$ & 0.73 & 0.68 & $0.69 \pm 0.06$ & $0.56 \pm 0.24$ \\
\hline B. bohemicus & 0.89 & 0.63 & $0.77 \pm 0.11$ & $0.61 \pm 0.22$ & 0.77 & 0.67 & $0.78 \pm 0.06$ & $0.71 \pm 0.07$ \\
\hline B. cryptarum & 0.81 & 0.60 & $0.7 \pm 0.09$ & $0.81 \pm 0.17$ & 0.69 & 0.59 & $0.66 \pm 0.11$ & $0.79 \pm 0.1$ \\
\hline B. rupestris & 0.79 & 0.58 & $0.75 \pm 0.03$ & $0.86 \pm 0.04$ & 0.72 & 0.67 & $0.74 \pm 0.05$ & $0.84 \pm 0.06$ \\
\hline B. ruderarius & 0.76 & 0.60 & $0.67 \pm 0.07$ & $0.85 \pm 0.08$ & 0.66 & 0.60 & $0.68 \pm 0.08$ & $0.86 \pm 0.05$ \\
\hline B. campestris & 0.68 & 0.57 & $0.64 \pm 0.02$ & $0.96 \pm 0.02$ & 0.62 & 0.57 & $0.61 \pm 0.04$ & $0.83 \pm 0.09$ \\
\hline B. terrestris & 0.62 & 0.53 & $0.61 \pm 0.02$ & $0.89 \pm 0.07$ & 0.59 & 0.55 & $0.58 \pm 0.01$ & $0.85 \pm 0.06$ \\
\hline B. hypnorum & 0.62 & 0.56 & $0.62 \pm 0.01$ & $0.77 \pm 0.12$ & 0.57 & 0.54 & $0.57 \pm 0.01$ & $0.77 \pm 0.11$ \\
\hline B. lapidarius & 0.61 & 0.56 & $0.61 \pm 0.02$ & $0.78 \pm 0.11$ & 0.57 & 0.56 & $0.56 \pm 0$ & $0.42 \pm 0.27$ \\
\hline B. pratorum & 0.60 & 0.54 & $0.58 \pm 0.01$ & $0.87 \pm 0.09$ & 0.56 & 0.54 & $0.56 \pm 0.01$ & $0.45 \pm 0.32$ \\
\hline B. pascuorum & 0.59 & 0.54 & $0.59 \pm 0.02$ & $0.7 \pm 0.13$ & 0.53 & 0.53 & $0.53 \pm 0.02$ & $0.34 \pm 0.27$ \\
\hline B. hortorum & 0.58 & 0.53 & $0.56 \pm 0.02$ & $0.82 \pm 0.12$ & 0.55 & 0.52 & $0.52 \pm 0.03$ & $0.74 \pm 0.15$ \\
\hline
\end{tabular}

Note: Full model and null model include all occurrence records. $95 \%$ Null shows the $95 \%$ quantile of 100 randomized null models of the same number of occurrence records in the same background space. Cross validation shows the mean and standard deviation AUC and Boyce index of the two best models from each of the five randomized cross validation folds (10 models).

from the HTR models were far more important on average for bumblebee species than others. Secondly, we observed that when grouped together into the predictors for the LTR models, the impact of the predictors on the species (whether they generally positively or negatively influenced habitat suitability as they increase) was not representative of the impact of the separated predictors.

For the arable class, the highest average variable importance was found for unregistered agricultural land (13\%; Figure 2a). Unregistered land had a positive impact on more species (26\% of species) than the aggregated class (16\%) and fewer negative impacts (32\% versus $42 \%$; Figure $2 \mathrm{~b}$ ). The other four arable classes showed lower average importance. Grain and potatoes were mostly negative while sugar beet and oilseed rape had little overall contribution to species distribution. The forest class differed least in variable importance between LTR and HTR models. In general, the same overall average importance of the single predictor (32\%) was shared between the three classes, coniferous, mixed and deciduous forest, in the HTR model (11\%, 9\% and 7\%). Mixed forest had the same positive effect as the aggregated forest class ( $47 \%$ of species), but a limited negative impact in comparison ( $11 \%$ and $37 \%$ of species). The aggregated grassland class showed the most differences between the LTR and HTR. Wetland and heathland occupy small areas in Belgium but had high average variable importance (both 8\%), which together was greater than the importance of the aggregated grassland class
(13\%). Both wetland (42\% of species) and semi-natural grassland (32\% of species) had positive impacts on many bumblebees. Seminatural grassland was also the only class with no negative impacts. Heathland is both positive and negative for $21 \%$ of species.

Permanent crops showed little difference as fruit trees make up all permanent crops used in the analysis. However, the overall importance of fruit trees was far lower indicating an impact of model complexity. Finally, a large part of the importance of the urban classification used in the LTR models (25\%) was indicated by residential areas (10\%). The other three classifications had less importance on average for bumblebees. The general impact of urban classes also changed considerably when split, we see that residential and park areas were positive for some ( $16 \%$ and $26 \%$ of species) and negative for others ( $32 \%$ and $26 \%$ of species) while sealed surfaces and recreation areas were almost exclusively negative (68\% and $53 \%$ of species) or neutral. Full details of which species were positively and negatively affected by each LU class can be seen in Table S2.3.

\subsection{Projection differences between HTR and LTR models}

We examined the impact of high thematic resolution explanatory LU variables for modelling the future distribution of Belgian bumblebee 

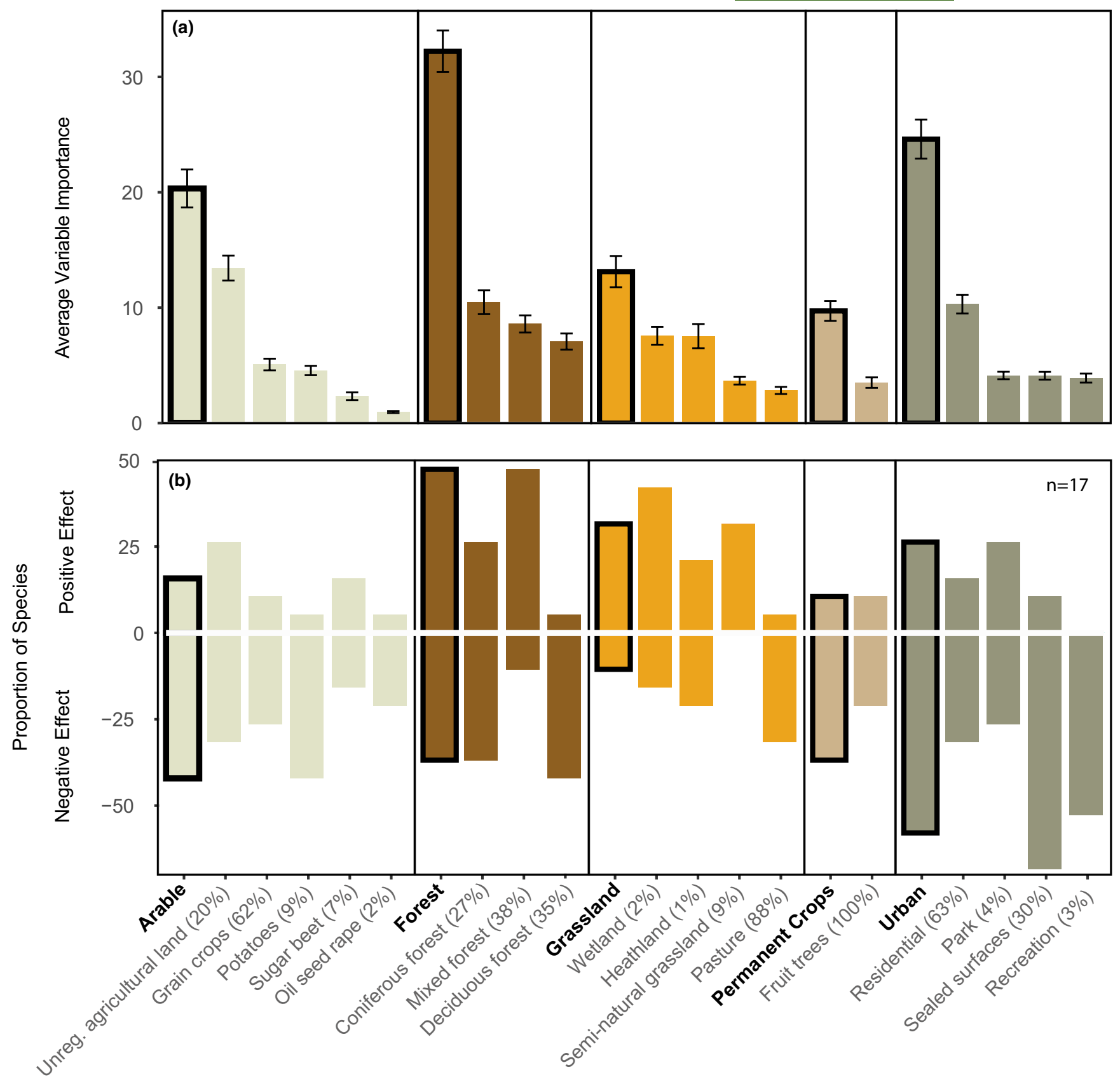

FIGURE 2 Variable Importance of land use (LU) variables. (a) Average variable importance and standard error for all variables, grouped by classification. (b) Proportion of bumblebee species for which the variable has a positive or negative overall correlation ( $>0.7$ or $<-0.7$ Pearson's correlation coefficient), $n=17$ (species with correlation $<0.7$ and $>-0.7$ are not shown). Black outline indicates the class used in the lower thematic resolution modelling. Percentage values in brackets indicate the percentage that the high thematic land use classification makes up of the total aggregated lower thematic resolution classification, for example, Grain crops represents $62 \%$ of Arable land use.

species using multivariate regression models. The best regression models, as chosen by BIC, for each of the four response variables had a similar fixed effects structure. All best models included model resolution, and two included the interaction with occurrence rank (percentage loss and change in division index) as explanatory variables. In no case did the scenario have a significant impact on the distribution change measure.
We observed statistically clear differences between HTR and LTR projections when analysing the component measures of distribution change. Specifically, percentage loss and gain of suitable grid cells were projected to be higher under HTR models (Figure 3a,b; loss, mean difference $=9.7 \% \pm 1.9, t=-5.1,95 \% \mathrm{Cl}$ around estimate $=5.9 \%-13.4 \%$; gain, mean difference $=13.3 \% \pm 1.5, t=-9.0$, $95 \% \mathrm{Cl}=10.4 \%-16.3 \%$; gain). Percentage loss was lower for more 

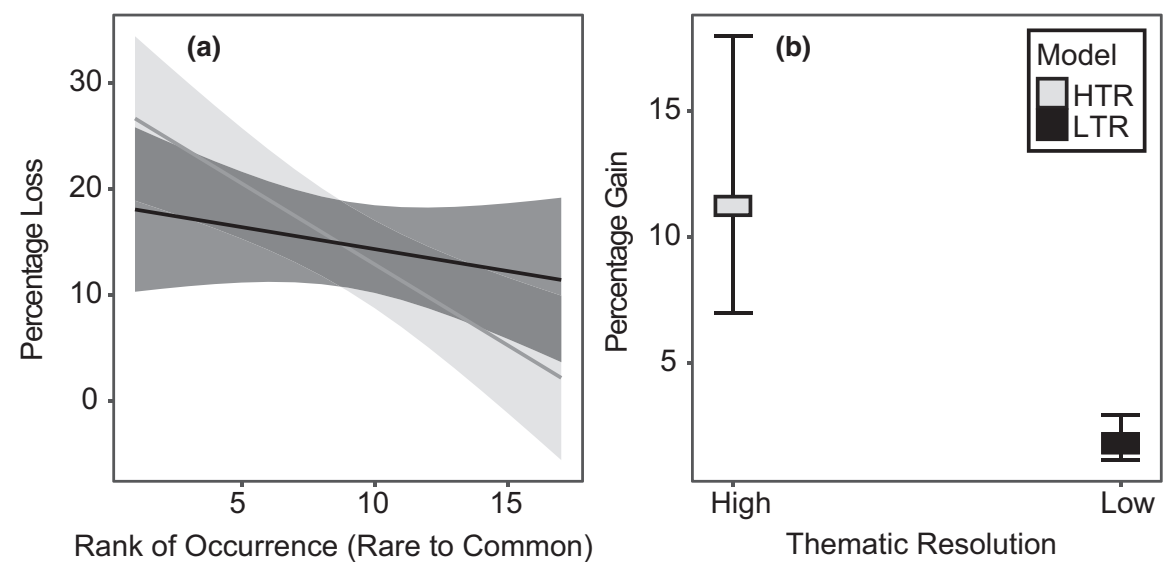

Rank of Occurrence (Rare to Common)

Thematic Resolution
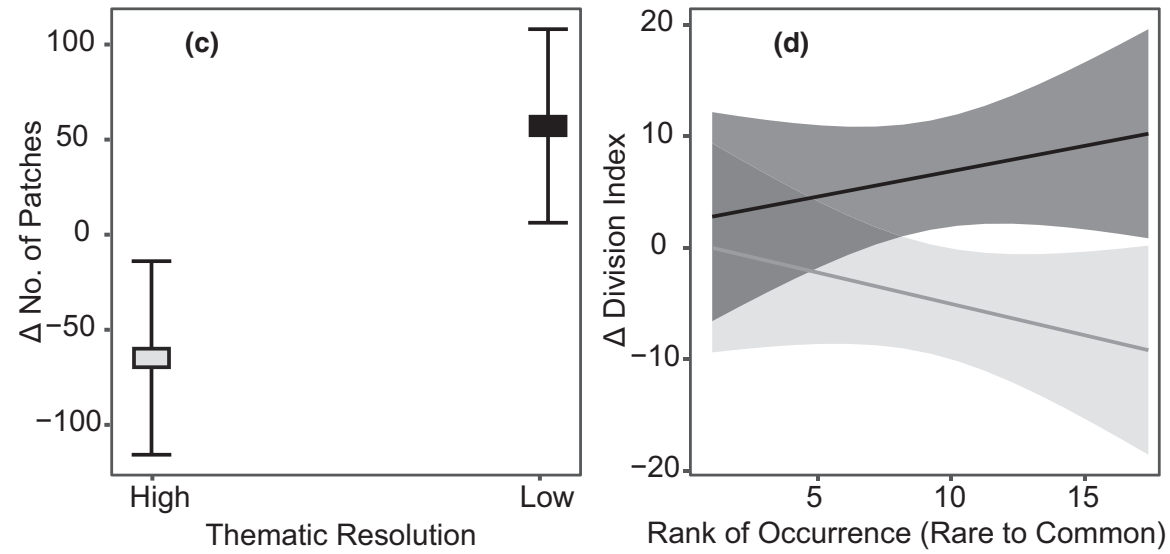

FIGURE 3 Fitted mixed effects model predictions for projected distribution changes of Belgian bumblebees. (a) Percentage range loss, number of cells occupied in present no longer occupied in 2035 divided by total number of cells occupied in present (best model includes the interaction between rank of occurrence and model resolution as fixed effects). (b) Percentage range gain, number of cells occupied in 2035 that were not occupied in the present divided by total number of cells occupied in present (best model includes model resolution as the fixed effect). (c) Change $(\Delta)$ in number of patches, increase or decrease in number of unique habitat patches per species between the present and 2035 (best model includes model resolution as the fixed effect). (d) Change in ( $\Delta$ ) division index, measure of the probability of two random suitable habitat cells not coming from the same patch (best model includes the interaction between rank of occurrence and model resolution as fixed effects). Model thematic resolution is either high (HTR; grey) or low (LTR: black). Rank of occurrence is the ordered ranking of each species rare to common based on the number of occurrence records used in the species distribution models. All models were first fit with the model structure $\gamma=$ Resolution*Rank of Occurrence + Scenario $+(1 \mid$ Species) and for each response variable the best model was chosen using Bayesian Information Criteria (BIC)

common species under HTR models compared to LTR models (Figure 3a). However, for percentage loss there was a statistically influential interaction between occurrence rank and model thematic resolution, HTR models showed a steeper negative trend, with greater loss predicted for rare species and less loss predicted for common species compared to LTR models (Figure 3a; $\beta=1.1 \pm 0.2$; $95 \% \mathrm{Cl}=0.75-1.48$. Furthermore, under LTR present range size was larger for all species (Figure S2.3).

The HTR models project a decrease in the number of patches of suitable habitat, whereas LTR models project increases (Figure 3c; mean difference: $122 \pm 16, t=7.6,95 \% \mathrm{Cl}=90-154)$. Mean patch area is projected to increase for HTR models (mean: 629 ha) and decrease for LTR models suggesting the loss of small patches for HTR models and increased splitting of larger patches for LTR models (mean: $-1,414$ ha; see Table S2.4 for full details). For HTR models, the division index is projected to stay the same for rare species and decrease for more common species. For LTR models the division index is projected to remain unchanged for rare species but to increase for common species. This is demonstrated by a statistically clear interaction between occurrence rank and thematic resolution, the relationship shifts from negative to positive from HTR to LTR models ( $\beta=1.04, t=3.14,95 \% \mathrm{Cl}=0.39-1.69$; Figure $3 \mathrm{~d}$ ). For full details on the multivariate mixed effects models and the underlying data per species see Table S2.5 and Figures S2.4-S2.6.

\section{4 | DISCUSSION}

We observed statistically clear differences in model performance, variable importance and effect, and distribution changes for Belgian bumblebees when comparing SDMs with high thematic resolution LUC predictors and low thematic resolution LUC predictors. This supports the hypothesis that increased thematic resolution is required to better capture the potential effect of LUC on future trends 
of bumblebee species. These results indicate that an absence of detailed LU classes could result in inaccuracies when projecting scenarios of biodiversity changes.

Land use change will affect biodiversity in the future (Newbold, 2018), therefore efforts should be made to produce the best models to measure these potential impacts. One such way is with LUC models that provide comprehensive predictors of relevant LU types (Verburg et al., 2013), to use as predictors in SDMs. Our analyses involved the coupling of two distinct LUC models to provide detailed classes of LU for the total area of Belgium and were able to provide outputs relevant for modelling the distribution of biodiversity in the future. We showed the added value of models such as ADAM (Beckers et al., 2018) outside their own research context. The possibility to integrate agent-based models of farmer decision-making and socio-economic drivers of LUC at the parcel level provides unprecedented detail for scenarios of biodiversity change.

There was a clear distinction in SDM projections when splitting aggregated LU classes from classifications often used in biodiversity scenarios (Spangenberg et al., 2012; Titeux et al., 2016). Coarse classification does not allow causal inference on the LU, while 17 classes provide a greater scope to directly attribute LU classes to species presence (Thuiller, Araújo, et al., 2004; Thuiller, Brotons, et al., 2004). Not only does model performance improve, supporting already observed results in SDMs (Cord et al., 2014; Liang et al., 2013; Nuse et al., 2015; Rengstorf et al., 2014), but we also observed that splitting aggregated classes resulted in a disparity between the impacts on species' future distributions. Certain sub-classes appear to have a different overall effect on the habitat suitability predictions for species than the aggregated LTR class does. For example, semi-natural grassland, which was exclusively positive for bumblebees, should be distinguished from more intensive agricultural grasslands. Seminatural grasslands are known to be habitats with high plant (Pykälä et al., 2005) and insect diversity (Duelli \& Obrist, 2003). However, the level of detail of LUC predictors used here can still be improved and there is an absence of predictions related to actual on the ground LU management (Titeux et al., 2016). For example, increased detail regarding management decisions on grasslands, such as grazing intensity and mowing, would also influence projected suitability for biodiversity (Söderström et al., 2001; Tanis et al., 2020). Heathland has a relatively limited extent in Belgium but has a comparatively high importance and was both limiting and facilitating for different species of bumblebees. Heathland is likely to be limiting to those bumblebee species not adapted to the specialized feeding resources present in these habitats (Moquet et al., 2016). However, for those that are specialized, for example, B. magnus Vogt, 1911, and B. jonellus Kirby, 1802, (Goulson et al., 2005), it is the most relevant class to determine present and future distributions. When aggregated, the distribution of these species will be incorrectly estimated.

The results also reiterate the importance of urban areas for certain common bumblebees (Baldock et al., 2015; Hernandez et al., 2009). The benefits of the CCA model aspect of the full LUC model are that land demands can be applied to potential population growth and policy decisions to determine where new housing and residential areas are likely to be in the future (White et al., 1997). In terms of the bumblebee species found regularly in urban gardens, this is a great potential predictor. Urban areas are not equal in their suitability and considering sealed surfaces and parks as the same LU is not representative. Therefore, an example of a conclusion that could be drawn from the HTR results is that increasing inner city green areas and encouraging residential gardens with appropriate resources (Cane, 2005), managed for biodiversity, may be beneficial for bumblebees in the future, a conclusion that could not be drawn from the LTR models. The distinction between arable classes, while having a more moderate impact than the other classes, still shows some clear differences. A more useful categorization for agricultural parcels would likely include both use and management, such as the intensity of the agriculture practices present at a site. For example, organic agricultural practices have been shown to stabilize species richness of bumblebees (Carrié et al., 2018). This is illustrated by unregistered agricultural land, which is the most important subclass and potentially has a high ecological value (Beilin et al., 2014). Unregistered agricultural land represents fields that are not registered with the government for income support. They represent land used for low-intensity hobby farming as well as unmanaged abandoned land. Low intensity and abandoned agricultural land have high potential as hotspots of diversity and as more farmers are encouraged to abandon land margins this may represent an important aspect of future LUC (Beilin et al., 2014; Kuemmerle et al., 2013). Agriculture in Europe is perhaps at a turning point (Pe'er et al., 2019). Future agroecological practices, including the restoration of an ecological network and new crop choices and management, will likely have a positive impact on many pollinator species like bumblebees (Varah et al., 2020).

We observed a clear difference between projections of future species' distribution patterns between HTR and LTR models. It is well known that LU classes are important to understand the distribution of bumblebees in the past, present and future (Aguirre-Gutiérrez et al., 2017; Marshall et al., 2018; Vray et al., 2019). This is also in line with best practice for SDMs. Araújo et al. (2019) specifically stress the importance of considering relevant environmental and biotic variables and indicate that researchers should hold back on projecting biodiversity if dynamic, relevant predictors are unavailable. One of the key impacts of LTR models, which in turn affected the projected distribution shifts, was the predicted extent of each species in the present day. Greater potential increases and decreases in suitable habitat under HTR models suggest that a more accurate present-day representation of extent from HTR models as opposed to a likely over-estimation with LTR models alongside a more complex mosaic of habitat conditions increases the probability of species shifting in changing landscapes. These results are also likely linked to model complexity, which is higher in the high thematic resolution models and will result in a stronger fit between species and the land use predictors. This is a characteristic of increased thematic resolution and the reason why we limited complexity in other areas of the models, by using minimal features (linear and quadratic only) in the MaxEnt models and maintaining all other model options the same. 
There is an inherent uncertainty in future projections of biodiversity (Thuiller, 2004); however, due to the ecological knowledge of the habitat requirements and preferences of some bumblebees, we can be reasonably confident that HTR models are performing better at capturing the relevant niche of bumblebees (Vray et al., 2019; Williams et al., 2007).

The final aim of this research was to highlight whether species area of occupancy impacted the relationship between LTR and HTR models. Rarer and localized bumblebee species are often those with the most specific habitat requirements regarding their nesting and feeding resources (Goulson, 2010; Potts et al., 2005; Svensson et al., 2000). We observed that the relationship between predictions of loss for rare to common species are more extreme for HTR models. The results suggest that due to the over-estimation of suitable habitat, LTR models are likely to incorrectly predict loss for those species whose specific requirements are not captured by LTR predictors. This supports results found for Mexican tree species where the necessity for detailed LU varied by species and was dependent on the distinctiveness of the species' habitat requirements (Cord et al., 2014).

One of the most striking results is the apparent separate impact of the two modelling procedures on the future connectivity between suitable habitat patches. We observed that LTR models predict on average a large increase in number of patches, whereas HTR predict a large decrease. Due to the changes in patch area the results suggest that under HTR, species are losing small suitable habitat patches while under LTR large areas of suitable habitat are being split. We also observed that, under LTR models, common species are predicted to increase in division whereas under HTR, they are projected to decrease. This has substantial implications, as the number of patches is related to connectivity between populations and potential future dispersal and the ability to track other environmental changes and move into future suitable habitat (Pearson $\&$ Dawson, 2003). Therefore, predicted decreases in the number of patches may provide indications of useful areas to protect and conserve where populations may be able to connect. Furthermore, agricultural LUC models often have the greatest amount of uncertainty compared to other landscapes (Alexander et al., 2017). Therefore, the change in number of patches and connectedness of suitable habitat may also be due to the increased model complexity and associated uncertainty of the improved LUC models.

It is important to note that the main aim of this research was to assess the importance of high thematic resolution LU maps in SDM. Other important decisions need to be made for any SDMs being produced for decision-making, including the use of climate change, soil characteristics and biotic interactions as predictors (Araújo et al., 2019; Wisz et al., 2012). The addition of these variables will also likely improve model performance for common habitat generalists which show here lower model performance. The impact of climate, although known to be an important parameter for bumblebees (Rasmont et al., 2015), was not included. This means the resulting projections are not representative of future ranges but specifically indicate the impact of LUC at a high resolution. To accurately model the impacts of high-resolution LUC alongside climate change would require collection records from the whole range of the species with correspondingly high-resolution LUC data, which are currently unavailable (Thuiller, Araújo, et al., 2004; Thuiller, Brotons, et al., 2004; Titeux et al., 2016). As more detailed LUC models begin to be produced at larger scales, research including climate change will result in projections more applicable to and useful in policy-making processes (Porfirio et al., 2014). We hypothesize that, like the impacts of climate change when adding LUC (Marshall et al., 2018), higher thematic resolution LUC would provide more accurate projections of range change, but within the broader climate and habitat envelopes of the species.

In summary, the implications of using only LTR LUC predictors in SDMs could be wide ranging. The evidence here suggests that in the absence of HTR LUC variables using those with a coarse thematic resolution may not just lead to over predictions. Indeed, they may show contrasting trends, which has the potential to negatively impact any conservation decision made after observing the mapped projections (Araújo et al., 2019; Porfirio et al., 2014). Higher resolution predictors appear to provide a more accurate representation of the present-day habitat suitability, capturing more specialized habitat types occupied by rare and localized species. These specialized habitats can often be protected and managed. When producing biodiversity scenarios, particularly those likely to be used for conservation decision-making, the greatest available detail should be used at all stages of the modelling process. Therefore, a concerted effort should be made to produce LUC models of ecological significance, using wide-ranging techniques, to produce relevant, detailed predictors for use in modelling future species distribution patterns.

\section{ACKNOWLEDGEMENTS}

This research was supported by the Belgian Science Policy (BELSPO; Project BR/132/A1/BELBEES and grant BR/121/A2/MASC) and the KULeuven under a DOC-mandate. Special thanks go to Lien Poelmans and Karolien Vermeiren for the support on the land use data from their work in the GRoWaDRISK project (BELSPO). We thank Stephane De Greef, for his organization of the Brussels bumblebee occurrence data. We also thank the numerous recorders who collected occurrence records of Bumblebees, in particular, members of Natuurpunt and the group Aculea. Finally, we would like to thank the two anonymous reviewers for their critical reading of the manuscript and the valuable comments they provided.

\section{DATA AVAILABILITY STATEMENT}

The environmental data used as predictors in the species distribution models are available at https://github.com/lmar116/HighT hematicBumblebees. The species occurrence data were collated as part of the Multidiciplinary assessment of BELgian wild BEE decline to adapt mitigation management policy (BELBEES) project and are downloadable at: https://doi.org/10.15468/dbx74x.

\section{ORCID}

Leon Marshall iD https://orcid.org/0000-0002-7819-7005 


\section{REFERENCES}

Aguirre-Gutiérrez, J., Kissling, W. D., Biesmeijer, J. C., WallisDeVries, M. F., Reemer, M., \& Carvalheiro, L. G. (2017). Historical changes in the importance of climate and land use as determinants of Dutch pollinator distributions. Journal of Biogeography, 44(3), 696-707. https://doi. org/10.1111/jbi.12937

Alexander, P., Prestele, R., Verburg, P. H., Arneth, A., Baranzelli, C., Batista e Silva, F., Brown, C., Butler, A., Calvin, K., Dendoncker, N., Doelman, J. C., Dunford, R., Engström, K., Eitelberg, D., Fujimori, S., Harrison, P. A., Hasegawa, T., Havlik, P., Holzhauer, S., ... Rounsevell, M. D. A. (2017). Assessing uncertainties in land cover projections. Global Change Biology, 23(2), 767-781. https:// doi.org/10.1111/gcb.13447

Araújo, M. B., Anderson, R. P., Márcia Barbosa, A., Beale, C. M., Dormann, C. F., Early, R., Garcia, R. A., Guisan, A., Maiorano, L., Naimi, B., O'Hara, R. B., Zimmermann, N. E., \& Rahbek, C. (2019). Standards for distribution models in biodiversity assessments. Science Advances, 5(1), eaat4858. https://doi.org/10.1126/sciadv.aat4858

Austin, M. P., \& Van Niel, K. P. (2011). Improving species distribution models for climate change studies: Variable selection and scale. Journal of Biogeography, 38(1), 1-8. https://doi. org/10.1111/j.1365-2699.2010.02416.x

Bakker, M. M., Alam, S. J., van Dijk, J., \& Rounsevell, M. D. A. (2015). Land-use change arising from rural land exchange: An agent-based simulation model. Landscape Ecology, 30(2), 273-286. https://doi. org/10.1007/s10980-014-0116-x

Baldock, K. C. R., Goddard, M. A., Hicks, D. M., Kunin, W. E., Mitschunas, N., Osgathorpe, L. M., Potts, S. G., Robertson, K. M., Scott, A. V., Stone, G. N., Vaughan, I. P., \& Memmott, J. (2015). Where is the UK's pollinator biodiversity? The importance of urban areas for flower-visiting insects. Proceedings of the Royal Society B: Biological Sciences, 282(1803), 20142849. https://doi.org/10.1098/rspb.2014.2849

Barbet-Massin, M., Thuiller, W., \& Jiguet, F. (2012). The fate of European breeding birds under climate, land-use and dispersal scenarios. Global Change Biology, 18(3), 881-890.

Beckers, V., Beckers, J., Vanmaercke, M., Van Hecke, E., Van Rompaey, A., \& Dendoncker, N. (2018). Modelling farm growth and its impact on agricultural land use: A country scale application of an agentbased model. Land, 7(3), 109. https://doi.org/10.3390/land7030109

Beckers, V., Poelmans, L., Van Rompaey, A., \& Dendoncker, N. (2020). The impact of urbanization on agricultural dynamics: A case study in Belgium. Journal of Land Use Science, 1-18. https://doi. org/10.1080/1747423X.2020.1769211

Beilin, R., Lindborg, R., Stenseke, M., Pereira, H. M., Llausàs, A., Slätmo, E., Cerqueira, Y., Navarro, L., Rodrigues, P., Reichelt, N., Munro, N., \& Queiroz, C. (2014). Analysing how drivers of agricultural land abandonment affect biodiversity and cultural landscapes using case studies from Scandinavia, Iberia and Oceania. Land Use Policy, 36, 60-72. https://doi.org/10.1016/j.landusepol.2013.07.003

Biesmeijer, J. C., Roberts, S. P. M., Reemer, M., Ohlemuller, R., Edwards, M., Peeters, T., \& Kunin, W. E. (2006). Parallel declines in pollinators and insect-pollinated plants in Britain and the Netherlands. Science, 313(5785), 351-354. https://doi.org/10.1126/science.1127863

Cane, J. H. (2005). Bees, pollination, and the challenges of sprawl. In E. A. Johnson, \& M. W. Klemens (Eds.), Nature in fragments: The legacy of sprawl (pp. 109-124). Columbia University Press.

Carrié, R., Ekroos, J., \& Smith, H. G. (2018). Organic farming supports spatiotemporal stability in species richness of bumblebees and butterflies. Biological Conservation, 227, 48-55. https://doi.org/10.1016/j. biocon.2018.08.022

Carvalheiro, L. G., Kunin, W. E., Keil, P., Aguirre-Gutiérrez, J., Ellis, W. N., Fox, R., Groom, Q., Hennekens, S., Van Landuyt, W., Maes, D., Van de Meutter, F., Michez, D., Rasmont, P., Ode, B., Potts, S. G., Reemer, M., Roberts, S. P. M., Schaminée, J., WallisDeVries, M. F.,
\& Biesmeijer, J. C. (2013). Species richness declines and biotic homogenisation have slowed down for NW-European pollinators and plants. Ecology Letters, 16(7), 870-878. https://doi.org/10.1111/ ele.12121

Ceballos, G., Ehrlich, P. R., Barnosky, A. D., García, A., Pringle, R. M., \& Palmer, T. M. (2015). Accelerated modern human-induced species losses: Entering the sixth mass extinction. Science Advances, 1(5), e1400253. https://doi.org/10.1126/sciadv.1400253

Chytrý, M., Wild, J., Pyšek, P., Jarošík, V., Dendoncker, N., Reginster, I., Pino, J., Maskell, L. C., Vilà, M., Pergl, J., Kühn, I., Spangenberg, J. H., \& Settele, J. (2012). Projecting trends in plant invasions in Europe under different scenarios of future land-use change. Global Ecology and Biogeography, 21(1), 75-87. https://doi.org/10.1111/ j.1466-8238.2010.00573.x

Cord, A. F., Klein, D., Mora, F., \& Dech, S. (2014). Comparing the suitability of classified land cover data and remote sensing variables for modeling distribution patterns of plants. Ecological Modelling, 272, 129-140. https://doi.org/10.1016/j.ecolmodel.2013.09.011

de Chazal, J., \& Rounsevell, M. D. A. (2009). Land-use and climate change within assessments of biodiversity change: A review. Global Environmental Change, 19(2), 306-315. https://doi.org/10.1016/j. gloenvcha.2008.09.007

De Rosa, M., Knudsen, M. T., \& Hermansen, J. E. (2016). A comparison of Land Use Change models: Challenges and future developments. Journal of Cleaner Production, 113, 183-193. https://doi. org/10.1016/j.jclepro.2015.11.097

Di Cola, V., Broennimann, O., Petitpierre, B., Breiner, F. T., D'Amen, M., Randin, C., Engler, R., Pottier, J., Pio, D., Dubuis, A., Pellissier, L., Mateo, R. G., Hordijk, W., Salamin, N., \& Guisan, A. (2017). ecospat: An $R$ package to support spatial analyses and modeling of species niches and distributions. Ecography, 40(6), 774-787. https://doi. org/10.1111/ecog.02671

Duelli, P., \& Obrist, M. K. (2003). Regional biodiversity in an agricultural landscape: The contribution of seminatural habitat islands. Basic and Applied Ecology, 4(2), 129-138. https://doi.org/10.1078/ 1439-1791-00140

Elith, J., Phillips, S. J., Hastie, T., Dudík, M., Chee, Y. E., \& Yates, C. J. (2011). A statistical explanation of MaxEnt for ecologists. Diversity and Distributions, 17(1), 43-57. https://doi.org/10.1111/ j.1472-4642.2010.00725.x

Engelen, G., Lavalle, C., Barredo, J. I., Meulen, M. V. D., \& White, R. (2007). The moland modelling framework for urban and regional land-use dynamics. In E. Koomen, J. Stillwell, A. Bakema, \& H. J. Scholten (Eds.), Modelling land-use change: Progress and applications (pp. 297-320). Springer Netherlands.

Engelen, G., Van Esch, L., Uljee, I., De Kok, J., Gobin, A., Poelmans, L., \& van der Kwast, J. (2011). Ruimtelijk-dynamisch Landgebruiksmodel voor Vlaanderen:Prototype v.5. Retrieved from https://ruimtemodel.vlaan deren/download//RuimteModel-Ruimtelijk-dynamisch_Landgebrui ksmodel_voor_Vlaanderen-Eindrapport.pdf

Engelen, G., White, R., \& Nijs, T. (2003). Environment explorer: Spatial support system for the integrated assessment of socio-economic and environmental policies in the Netherlands. Integrated Assessment, 4(2), 97-105. https://doi.org/10.1076/iaij.4.2.97.16707

European Commission. (2018). Integrated Administration and Control System (IACS). Retrieved from https://ec.europa.eu/agriculture/direc t-support/iacs_en

Ficetola, G. F., Maiorano, L., Falcucci, A., Dendoncker, N., Boitani, L., Padoa-schioppa, E., Miaud, C., \& Thuiller, W. (2010). Knowing the past to predict the future: Land-use change and the distribution of invasive bullfrogs. Global Change Biology, 16(2), 528-537. https://doi. org/10.1111/j.1365-2486.2009.01957.x

Goulson, D. (2010). Bumblebees: Behaviour, ecology, and conservation. Oxford University Press. 
Goulson, D., Hanley, M. E., Darvill, B., Ellis, J. S., \& Knight, M. E. (2005). Causes of rarity in bumblebees. Biological Conservation, 122(1), 1-8. https://doi.org/10.1016/j.biocon.2004.06.017

Guisan, A., Broennimann, O., Engler, R., Vust, M., Yoccoz, N. G., Lehmann, A., \& Zimmermann, N. E. (2006). Using niche-based models to improve the sampling of rare species. Conservation Biology, 20(2), 501511. https://doi.org/10.1111/j.1523-1739.2006.00354.x

Guisan, A., \& Thuiller, W. (2005). Predicting species distribution: Offering more than simple habitat models. Ecology Letters, 8(9), 993-1009. https://doi.org/10.1111/j.1461-0248.2005.00792.x

Happe, K., Balmann, A., Kellermann, K., \& Sahrbacher, C. (2008). Does structure matter? The impact of switching the agricultural policy regime on farm structures. Journal of Economic Behavior Organization, 67(2), 431-444. https://doi.org/10.1016/j.jebo.2006.10.009

Hernandez, J. L., Frankie, G. W., \& Thorp, R. W. (2009). Ecology of urban bees: A review of current knowledge and directions for future study. Cities and the Environment (CATE), 2(1), 3.

Hesselbarth, M. H. K., Sciaini, M., Nowosad, J., \& Hanss, S. (2019). landscapemetrics: Landscape metrics for categorical map patterns. $\mathrm{R}$ package version 1.1.

Hughes, A. C., Satasook, C., Bates, P. J. J., Bumrungsri, S., \& Jones, G. (2012). The projected effects of climatic and vegetation changes on the distribution and diversity of Southeast Asian bats. Global Change Biology, 18(6), 1854-1865. https://doi. org/10.1111/j.1365-2486.2012.02641.x

Jiménez-Valverde, A., \& Lobo, J. M. (2007). Threshold criteria for conversion of probability of species presence to either-or presence-absence. Acta Oecologica, 31(3), 361-369. https://doi.org/10.1016/j. actao.2007.02.001

Kallioniemi, E., Åström, J., Rusch, G. M., Dahle, S., Åström, S., \& Gjershaug, J. O. (2017). Local resources, linear elements and mass-flowering crops determine bumblebee occurrences in moderately intensified farmlands. Agriculture, Ecosystems \& Environment, 239, 90-100. https://doi.org/10.1016/j.agee.2016.12.039

Kerr, J. T., \& Ostrovsky, M. (2003). From space to species: Ecological applications for remote sensing. Trends in Ecology Evolution, 18(6), 299-305. https://doi.org/10.1016/S0169-5347(03)00071-5

Kerr, J. T., Pindar, A., Galpern, P., Packer, L., Potts, S. G., Roberts, S. M., Rasmont, P., Schweiger, O., Colla, S. R., Richardson, L. L., Wagner, D. L., Gall, L. F., Sikes, D. S., \& Pantoja, A. (2015). Climate change impacts on bumblebees converge across continents. Science, 349(6244), 177180. https://doi.org/10.1126/science.aaa7031

Kuemmerle, T., Erb, K., Meyfroidt, P., Müller, D., Verburg, P. H., Estel, S., Haberl, H., Hostert, P., Jepsen, M. R., Kastner, T., Levers, C., Lindner, M., Plutzar, C., Verkerk, P. J., van der Zanden, E. H., \& Reenberg, A. (2013). Challenges and opportunities in mapping land use intensity globally. Current Opinion in Environmental Sustainability, 5(5), 484493. https://doi.org/10.1016/j.cosust.2013.06.002

Liang, Y., He, H. S., Fraser, J. S., \& Wu, Z. (2013). Thematic and spatial resolutions affect model-based predictions of tree species distribution. PLoS One, 8(7), e67889. https://doi.org/10.1371/journ al.pone.0067889

Luoto, M., Virkkala, R., \& Heikkinen, R. K. (2007). The role of land cover in bioclimatic models depends on spatial resolution. Global Ecology and Biogeography, 16(1), 34-42. https://doi. org/10.1111/j.1466-8238.2006.00262.x

Marshall, L., Biesmeijer, J. C., Rasmont, P., Vereecken, N. J., Dvorak, L., Fitzpatrick, U., Francis, F., Neumayer, J., Ødegaard, F., Paukkunen, J. P. T., Pawlikowski, T., Reemer, M., Roberts, S. P. M., Straka, J., Vray, S., \& Dendoncker, N. (2018). The interplay of climate and land use change affects the distribution of EU bumblebees. Global Change Biology, 24(1), 101-116. https://doi.org/10.1111/gcb.13867

Martin, Y., Van Dyck, H., Dendoncker, N., \& Titeux, N. (2013). Testing instead of assuming the importance of land use change scenarios to model species distributions under climate change. Global Ecology and Biogeography, 22(11), 1204-1216. https://doi.org/10.1111/ geb.12087

Mateo, R. G., Croat, T. B., Felicísimo, Á. M., \& Muñoz, J. (2010). Profile or group discriminative techniques? Generating reliable species distribution models using pseudo-absences and target-group absences from natural history collections. Diversity and Distributions, 16(1), 84-94. https://doi.org/10.1111/j.1472-4642.2009.00617.x

McGarigal, K. (2015). FRAGSTATS help. University of Massachusetts.

Merow, C., Smith, M. J., \& Silander, J. A. (2013). A practical guide to MaxEnt for modeling species' distributions: What it does, and why inputs and settings matter. Ecography, 36(10), 1058-1069. https:// doi.org/10.1111/j.1600-0587.2013.07872.x

Moquet, L., Vanderplanck, M., Moerman, R., Quinet, M., Roger, N., Michez, D., \& Jacquemart, A.-L. (2016). Bumblebees depend on ericaceous species to survive in temperate heathlands. Insect Conservation and Diversity, 10, 78-93. https://doi.org/10.1111/ icad.12201

Newbold, T. (2018). Future effects of climate and land-use change on terrestrial vertebrate community diversity under different scenarios. Proceedings of the Royal Society B: Biological Sciences, 285(1881), 20180792. https://doi.org/10.1098/rspb.2018.0792

Nieto, A., Roberts, S. P. M., Kemp, J., Rasmont, P., Kuhlmann, M., García Criado, M., ... Michez, D. (2014). European Red List of bees. Luxembourg: Publication Office of the European Union.

Nuse, B. L., Cooper, R. J., \& Hunter, E. A. (2015). Prospects for predicting changes to coastal wetland bird populations due to accelerated sea level rise. Ecosphere, 6(12), 1-23. https://doi.org/10.1890/ es15-00385.1

Parker, D. C., Manson, S. M., Janssen, M. A., Hoffmann, M. J., \& Deadman, P. (2003). Multi-agent systems for the simulation of land-use and land-cover change: A review. Annals of the Association of American Geographers, 93(2), 314-337. https://doi. org/10.1111/1467-8306.9302004

Pearson, R. G., \& Dawson, T. P. (2003). Predicting the impacts of climate change on the distribution of species: Are bioclimate envelope models useful? Global Ecology and Biogeography, 12(5), 361-371. https:// doi.org/10.1046/j.1466-822X.2003.00042.x

Pe'er, G., Zinngrebe, Y., Moreira, F., Sirami, C., Schindler, S., Müller, R., Bontzorlos, V., Clough, D., Bezák, P., Bonn, A., Hansjürgens, B., Lomba, A., Möckel, S., Passoni, G., Schleyer, C., Schmidt, J., \& Lakner, S. (2019). A greener path for the EU Common Agricultural Policy. Science, 365(6452), 449-451. https://doi.org/10.1126/scien ce.aax3146

Phillips, S. J., Anderson, R. P., \& Schapire, R. E. (2006). Maximum entropy modeling of species geographic distributions. Ecological Modelling, 190(3-4), 231-259. https://doi.org/10.1016/j.ecolm odel.2005.03.026

Phillips, S. J., \& Dudík, M. (2008). Modeling of species distributions with Maxent: New extensions and a comprehensive evaluation. Ecography, 31(2), 161-175. https://doi.org/10.1111/j.0906-7590.2008.5203.x

Phillips, S. J., Dudík, M., Elith, J., Graham, C. H., Lehmann, A., Leathwick, J., \& Ferrier, S. (2009). Sample selection bias and presence-only distribution models: Implications for background and pseudo-absence data. Ecological Applications, 19(1), 181-197. https://doi. org/10.1890/07-2153.1

Polce, C., Maes, J., Rotllan-Puig, X., Michez, D., Castro, L., Cederberg, B., Dvorak, L., Fitzpatrick, Ú., Francis, F., Neumayer, J., Manino, A., Paukkunen, J., Pawlikowski, T., Roberts, S., Straka, J., \& Rasmont, P. (2018). Distribution of bumblebees across Europe. One Ecosystem, 3 , e28143. https://doi.org/10.3897/oneeco.3.e28143

Porfirio, L. L., Harris, R. M. B., Lefroy, E. C., Hugh, S., Gould, S. F., Lee, G., Bindoff, N. L., \& Mackey, B. (2014). Improving the use of species distribution models in conservation planning and management under climate change. PLoS One, 9(11), e113749. https://doi.org/10.1371/ journal.pone.0113749 
Potts, S. G., Vulliamy, B., Roberts, S., O'Toole, C., Dafni, A., Ne'eman, G., \& Willmer, P. (2005). Role of nesting resources in organising diverse bee communities in a Mediterranean landscape. Ecological Entomology, 30(1), 78-85. https://doi.org/10.1111/j.0307-6946.2005.00662.x

Préau, C., Isselin-Nondedeu, F., Sellier, Y., Bertrand, R., \& Grandjean, F. (2018). Predicting suitable habitats of four range margin amphibians under climate and land-use changes in southwestern France. Regional Environmental Change, 19(1), 27-38. https://doi.org/10.1007/s1011 3-018-1381-z

Pykälä, J., Luoto, M., Heikkinen, R. K., \& Kontula, T. (2005). Plant species richness and persistence of rare plants in abandoned semi-natural grasslands in northern Europe. Basic and Applied Ecology, 6(1), 25-33. https://doi.org/10.1016/j.baae.2004.10.002

Radosavljevic, A., \& Anderson, R. P. (2014). Making better Maxent models of species distributions: Complexity, overfitting and evaluation. Journal of Biogeography, 41(4), 629-643. https://doi.org/10.1111/ jbi.12227

Raes, N., \& ter Steege, H. (2007). A null-model for significance testing of presence-only species distribution models. Ecography, 30(5), 727736. https://doi.org/10.1111/j.2007.0906-7590.05041.x

Rasmont, P., Franzen, M., Lecocq, T., Harpke, A., Roberts, S., Biesmeijer, K., Castro, L., Cederberg, B., Dvorak, L., Fitzpatrick, U., Gonseth, Y., Haubruge, E., Mahe, G., Manino, A., Michez, D., Neumayer, J., Odegaard, F., Paukkunen, J., Pawlikowski, T., ... Schweiger, O. (2015). Climatic risk and distribution atlas of European bumblebees. Biodiversity and Ecosystem Risk Assessment, 10, 1-236. https://doi. org/10.3897/biorisk.10.4749

Rasmont, P., Heughebaert, A., Dendoncker, N., Boeve, J., de Graaf, D., Smagghe, G., Dufrene, M., d'Haeseleer, J., Paquet, J., \& Barbier, Y. (2019). Wild bees of Belgium. Belgian biodiversity platform. Occurrence dataset. https://doi.org/10.15468/dbx74x

Rasmont, P., Pauly, A., Terzo, M., Patiny, S., Michez, D., Iserbyt, S., \& Haubruge, E. (2005). The survey of wild bees (Hymenoptera, Apoidea) in Belgium and France (p. 18). Food and Agriculture Organisation.

Rengstorf, A. M., Mohn, C., Brown, C., Wisz, M. S., \& Grehan, A. J. (2014). Predicting the distribution of deep-sea vulnerable marine ecosystems using high-resolution data: Considerations and novel approaches. Deep Sea Research Part I: Oceanographic Research Papers, 93, 72-82. https://doi.org/10.1016/j.dsr.2014.07.007

Riordan, E. C., \& Rundel, P. W. (2014). Land use compounds habitat losses under projected climate change in a threatened California ecosystem. PLoS One, 9(1), e86487. https://doi.org/10.1371/journ al.pone.0086487

Rounsevell, M. D. A., Robinson, D. T., \& Murray-Rust, D. (2012). From actors to agents in socio-ecological systems models. Proceedings of the Royal Society Biological Sciences Series B, 367(1586), 259-269. https:// doi.org/10.1098/rstb.2011.0187

Sinclair, S. J., White, M. D., \& Newell, G. R. (2010). How useful are species distribution models for managing biodiversity under future climates. Ecology and Society, 15, 8. https://doi.org/10.5751/ES-03089 $-150108$

Söderström, B., Svensson, B., Vessby, K., \& Glimskär, A. (2001). Plants, insects and birds in semi-natural pastures in relation to local habitat and landscape factors. Biodiversity and Conservation, 10(11), 18391863. https://doi.org/10.1023/a:1013153427422

Sohl, T. L. (2014). The relative impacts of climate and land-use change on conterminous United States bird species from 2001 to 2075. PLoS One, 9(11), e112251. https://doi.org/10.1371/journal.pone.0112251

Spangenberg, J. H., Bondeau, A., Carter, T. R., Fronzek, S., Jaeger, J., Jylhä, K., Kühn, I., Omann, I., Paul, A., Reginster, I., Rounsevell, M., Schweiger, O., Stocker, A., Sykes, M. T., \& Settele, J. (2012). Scenarios for investigating risks to biodiversity. Global Ecology and Biogeography, 21(1), 5-18. https://doi.org/10.1111/j.1466-8238.2010.00620.x

Svensson, B., Lagerlöf, J., \& Svensson, B. G. (2000). Habitat preferences of nest-seeking bumble bees (Hymenoptera: Apidae) in an agricultural landscape. Agriculture, Ecosystems Environment, 77(3), 247-255. https://doi.org/10.1016/S0167-8809(99)00106-1

Tanis, M. M., Marshall, L., Biesmeijer, J. K., \& van Kolfschoten, L. (2020). Grassland management for meadow birds in the Netherlands is unfavourable to pollinators. Basic and Applied Ecology, 43, 52-63. https:// doi.org/10.1016/j.baae.2019.12.002

Thuiller, W. (2004). Patterns and uncertainties of species' range shifts under climate change. Global Change Biology, 10(12), 2020-2027. https://doi.org/10.1111/j.1365-2486.2004.00859.x

Thuiller, W., Araújo, M. B., \& Lavorel, S. (2004). Do we need land-cover data to model species distributions in Europe? Journal of Biogeography, 31(3), 353-361. https://doi.org/10.1046/j.0305-0270.2003.00991.x

Thuiller, W., Brotons, L., Araújo, M. B., \& Lavorel, S. (2004). Effects of restricting environmental range of data to project current and future species distributions. Ecography, 27(2), 165-172. https://doi. org/10.1111/j.0906-7590.2004.03673.x

Thuiller, W., Georges, D., Engler, R., \& Breiner, F. (2019). biomod2: Ensemble platform for species distribution modeling. R package version 3.3-7.1.

Titeux, N., Henle, K., Mihoub, J.-B., Regos, A., Geijzendorffer, I. R., Cramer, W., Verburg, P. H., \& Brotons, L. (2016). Biodiversity scenarios neglect future land-use changes. Global Change Biology, 22, 2505-2515. https://doi.org/10.1111/gcb.13272

van Proosdij, A. S. J., Sosef, M. S. M., Wieringa, J. J., \& Raes, N. (2015). Minimum required number of specimen records to develop accurate species distribution models. Ecography, 39(6), 542-552. https://doi. org/10.1111/ecog.01509

Varah, A., Jones, H., Smith, J., \& Potts, S. G. (2020). Temperate agroforestry systems provide greater pollination service than monoculture. Agriculture, Ecosystems \& Environment, 301, 107031. https://doi. org/10.1016/j.agee.2020.107031

Verburg, P. H., van Asselen, S., van der Zanden, E. H., \& Stehfest, E. (2013). The representation of landscapes in global scale assessments of environmental change. Landscape Ecology, 28(6), 1067-1080. https://doi.org/10.1007/s10980-012-9745-0

Vicente, J. R., Gonçalves, J., Honrado, J. P., Randin, C. F., Pottier, J., Broennimann, O., Lomba, A., \& Guisan, A. (2014). A framework for assessing the scale of influence of environmental factors on ecological patterns. Ecological Complexity, 20, 151-156. https://doi. org/10.1016/j.ecocom.2014.10.005

Vray, S., Rollin, O., Rasmont, P., Dufrêne, M., Michez, D., \& Dendoncker, N. (2019). A century of local changes in bumblebee communities and landscape composition in Belgium. Journal of Insect Conservation, 23(3), 489-501. https://doi.org/10.1007/s10841-019-00139-9

Walther-Hellwig, K., \& Frankl, R. (2000). Foraging habitats and foraging distances of bumblebees, Bombus spp. (Hym., Apidae), in an agricultural landscape. Journal of Applied Entomology, 124(7-8), 299-306. https://doi.org/10.1046/j.1439-0418.2000.00484.x

White, R., Engelen, G., \& Uljee, I. (1997). The use of constrained cellular automata for high-resolution modelling of urban land-use dynamics. Environment and Planning B: Planning and Design, 24(3), 323-343. https://doi.org/10.1068/b240323

Williams, P. H., Araújo, M. B., \& Rasmont, P. (2007). Can vulnerability among British bumblebee (Bombus) species be explained by niche position and breadth? Biological Conservation, 138(3-4), 493-505. https://doi.org/10.1016/j.biocon.2007.06.001

Wisz, M., Dendoncker, N., Madsen, J., Rounsevell, M., Jespersen, M., Kuijken, E., \& Cottaar, F. (2008). Modelling pink-footed goose (Anser brachyrhynchus) wintering distributions for the year 2050: Potential effects of land-use change in Europe. Diversity and Distributions, 14(5), 721-731. https://doi. org/10.1111/j.1472-4642.2008.00476.x

Wisz, M. S., Pottier, J., Kissling, W. D., Pellissier, L., Lenoir, J., Damgaard, C. F., Dormann, C. F., Forchhammer, M. C., Grytnes, J.-A., Guisan, A., Heikkinen, R. K., Høye, T. T., Kühn, I., Luoto, M., Maiorano, 
L., Nilsson, M.-C., Normand, S., Öckinger, E., Schmidt, N. M., ... Svenning, J.-C. (2012). The role of biotic interactions in shaping distributions and realised assemblages of species: Implications for species distribution modelling. Biological Reviews, 88(1), 15-30. https:// doi.org/10.1111/j.1469-185X.2012.00235.x

\section{BIOSKETCH}

Leon Marshall is interested in the patterns and drivers of biodiversity at the landscape scale. His work often focuses on the diversity of wild bees. He and the other authors collaborate on questions of wild bee diversity in Belgium and their intersection with landscape processes.

Author contributions: LM, VB, ND and PR conceived the ideas and LM, VB and ND designed the methodology. VB, SV, PR and NV collected, organized and managed the data. LM and VB performed the analyses of the data. All authors were involved in writing the manuscript.

\section{SUPPORTING INFORMATION}

Additional supporting information may be found online in the Supporting Information section.

How to cite this article: Marshall L, Beckers V, Vray S, Rasmont P, Vereecken NJ, Dendoncker N. High thematic resolution land use change models refine biodiversity scenarios: A case study with Belgian bumblebees. J Biogeogr 2020;00:1-14. https://doi.org/10.1111/jbi.14000 